Bridges, P. K., Bartlett, J. R., Hale, A. S., et al (1994) Psychosurgery: stereotactic subcaudate tractotomy - an indispensable treatment. British Journal of Psychiatry. 165. $599-611$

- Hodgkiss, A. D. \& MaLzaA, A. L. (1995) Practical management of treatment-resistant affective disorders. British Journal of Hospital Medicine, 84, 501-506.

P. K. BRIDGES, The Geoffrey Knight Unit for Affective Disorders, Maudsley Hospital, London SE5 8AZ

\section{Supervision registers: operational problems}

Sir: Mandatory 'supervision registers for mentally-ill people' were controversially implemented in 1994 to 'facilitate the effective prioritization of care' (NHS Management Executtive, 1994). The operation of this procedure was evaluated for al relevant NHS 'provider units' in East Anglia between June and November 1995. Data were obtained on randomly-chosen census days (one for each unit).

One hundred and forty patients were registered from a total population of 2.7 million and there was considerable variation between provider units in the number of registered patients/ 100000 of population (i.e. between 0.4-12.4) Sixty men and 19 women were considered to present a serious risk of violence to others.

Nine of the 11 Trusts had each developed a specific proforma to be used as the written record of the 'supervision register'. However, for most of them, headings for various items of information 'required' by the NHS Management Executive had been omitted. A distribution of copies was not specified for five proformas, while in no case was the keyworker identified as requiring a routine copy. The responsibility for completing the proforma was specified in only two units and for 9 registers, there was no mechanism for recording and communicating updated information. Each of the 'supervision registers' had a parallel computerised recording system, but, for some systems, not all the written information was routinely transferred to the computerised record.

Supervision registers were often found to contain out-of-date information and there were discrepancies between written and computerised data. Information that was a 'required consent' was often missing and some key workers were unaware that certain patients were registered.

Although the initial aim of the procedure was to prioritise care, 'supervision registers' also have the potential to identify, monitor, and assist in the planning for the needs of those patients who require the most intervention and care. This survey demonstrates that further attention needs to be given to clarifying patient selection and implementing adequate administrative procedures.

NHS MANAGEMENT EXEcuttive (1994) Introduction of Supervision Registers for Mentally-III People from 1 April 1994. HSG (94)5. Leeds: NHSME.

Jonathan H. DOWSON; PAMEla SUSSAMS, Cambridge University Department of Psychiatry. E4, Addenbrooke's Hospital, Cambridge CB2 2QQ; and OLWEN WILLIAMS, Regional Clinical Audit Team (Anglia), The Clinical School Addenbrooke's Hospital

\section{Clinical involvement by medical secretaries and receptionists: a questionnaire survey}

Sir: Medical secretaries and reception staff working in psychiatry are expected to deal with difficult and distressed patients and carers. The manner in which they do this gives an important first impression of the clinical service. In order to assess the clinical involvement of secretarial and reception staff within a mental health trust a questionnaire was sent to the relevant employees.

Thirty completed forms were returned out of $\mathbf{5 0}$ sent. The respondents were an experienced group (median time spent in psychiatry was 5 years, range 2-28) of 21 secretaries and 9 receptionists. All respondents had been asked for clinical advice by patients or carers which they felt unqualified to give. Many had offered to give a patient or carer informal support (18 face-to-face and 25 by telephone). Most respondents had received suicide threats (26 to their face and 17 on the telephone). Approximately half had been threatened themselves (14 in person and 17 on the telephone).

Only six of the 30 respondents had received any training in dealing with distressed or aggressive patients or carers, but 28 thought that such training would be helpful. Most staff who worked office hours had the opportunity to discuss their concerns about patients with clinical staff (15/ $20)$ but only four out of the 10 who often worked out-of-hours.

These results demonstrate high levels of clinical involvement by secretarial and reception staff and have indicated problem areas (working out-ofhours, on reception and in the drug/alcohol unit). A training and supervision need, quite separate from any issues of remuneration in recognition of such involvement, has been identified and is now being addressed. I would expect similar findings in other mental health units.

SIMON THACKER, Department of Health Care of the Elderly, Medical School, Nottingham University Hospital, NG7 2UH 